\title{
Introduction
}

DOI: $10.19195 / 2084-4107.11 .2$

29 December 2017 marks the start of the Polish national winter expedition to $\mathrm{K} 2(8,611$ metres above sea level) — the highest mountain of the Karakorum and the second highest mountain in the world - the last eight-thousanders never climbed in winter. The expedition is composed of thirteen outstanding climbers representing several generations. Its head is the legendary Polish climber Krzysztof Wielicki, who together with Leszek Cichy made the first winter ascent of Mount Everest (8,848 metres above sea level) on 17 February 1980. If the early 2018 expedition is successful, the Polish mountaineers will become part of the history of world Himalayan mountaineering as the first who began and ended the golden era of first winter ascents of eight-thousanders.

It is a pity that the members of this national expedition do not include a woman, despite efforts by eminent female mountaineers to have women included. It is worth pointing out at this point that Polish female climbers occupy a prominent position in the history of female Himalayan mountaineering.

Significantly, the preparations for the upcoming expedition have had a lot of publicity. Its participants take part in meetings all over Poland, reports on the professional training sessions of the "ice warriors" can be found on social media, radio stations interview them. All this generates great interest in society as well as among a growing number of amateurs, followers of mountaineering and lovers of mountains seen as an interesting area of exploration and recreation. In recent years there has been another wave of fascination with mountains and mountaineering as well as clear commercialisation of high mountaineering, which hitherto has been accessible only to elites. This is evidenced also by the intense growth of the so-called exploration literature dealing with e.g. high mountains and mountaineering biographies. The participants in the national K2 expedition include authors of recent very popular autobiographies and exploration books, to name just Krzysztof Wielicki, Adam Bielecki or Denis Urubko (Polish citizen since 2015), one of the most distinguished mountaineer of our times, two-time winner of the Piolet d'Or. In a 2014 collection of memoirs and stories, entitled A Lieutenant's Ice Axe, Urubko, trying to answer one of the most frequent questions posed to high mountain climbers, wrote that

climbing attracts precisely because it enables people to be themselves, to find their arguments in the stream of the existing ones, to get to know their limits. It makes life interesting; it gives freedom on the brink of physical and mental endurance. If we were to compare them, it will turn 
out that one year spent in a risky fight will be worth more than a century lived boringly and quietly ${ }^{1}$.

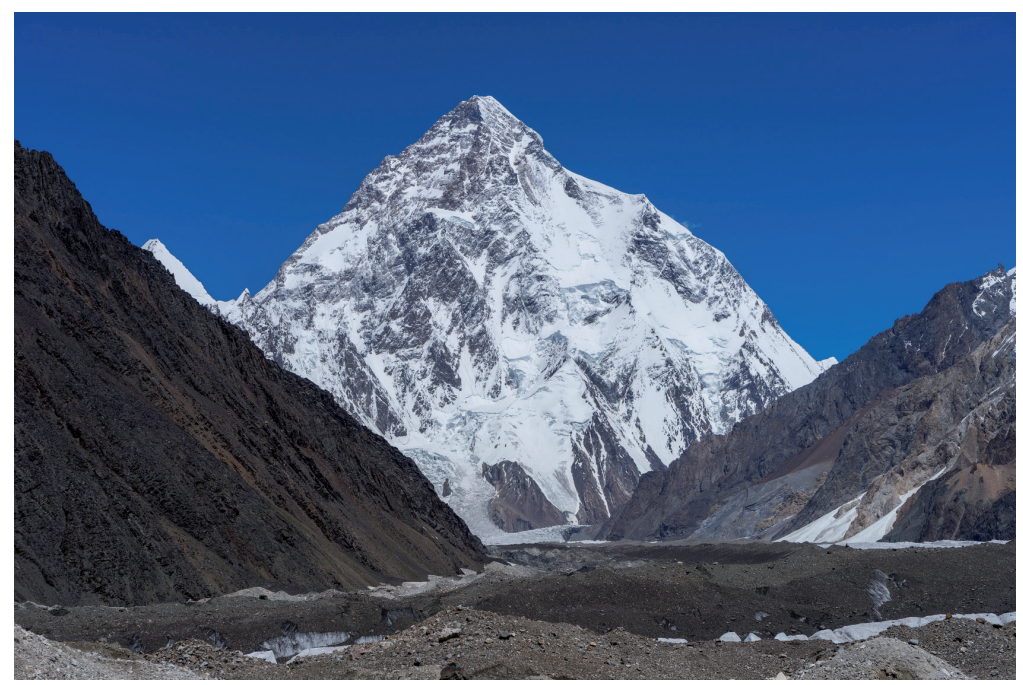

\section{K2,@ skazzjy/Fotolia}

This statement, clearly pointing to the mountains as a type of space to which we attribute the significance and function of a multifaceted boundary, from the topographic to psychological and biological dimensions, is one of many recurring suggestions or observations by past and present mountaineers. In a recent conversation with Olga Gordziejew, for an interview broadcast by Radio Białystok as part of the station's "Ucho na świat" (Ear to the World) programme, Adam Bielecki listed, among the motives prompting people to undertake activities in the mountains, a desire to overcome one's limitations, psychological and physiological barriers. Referring to the planned K2 expedition, as its official member he observed incisively that so far "more people have flown to space than have stood on an eight-thousander in winter". At the same time he stressed that "it is one of the greatest exploration challenges of the modern world, still nearly impossible".

It is, therefore, not surprising that research today also encompasses the relations between space, and human psyche and activity, space including the mountains, especially high mountains, which are subjected to a growing anthropogenic impact every year. What comes to the fore in this context is research into transgression, a phenomenon described already thirty years ago by Józef Kozielecki, expanding and complementing his concept of "transgressive man", homo transgressivus, which is an excellent tool to describe the condition of a broadly defined group of climbers exploring various mountains. They can be said, given their constant desire to cross and expand the limits of the biological and psychological

${ }^{1}$ D. Urubko, Czekan porucznika (A Lieutenant's Ice Axe), transl. A. Abilbayeva et al., Ząbkowice Śląskie 2014, p. 283. 
endurance of the human body in confrontation with the wild, "alienated" nature, to have become new "heroes of our times", adored by the media and admired by people craving spectacular successes.

The present, eleventh volume of Góry - Literatura - Kultura (Mountains Literature - Culture) contains an extensive selection of methodologically varied studies and sketches devoted to two inextricably linked categories of boundaries and transgression in the context of broadly understood mountain themes. It features papers by several generations of scholars representing Polish and foreign research centres. The studies are historical and overview-like in nature, and, at the same time, contain diagnoses of contemporary phenomena. The German-language papers have been published in two versions - original and in translation into Polish - which, according to the editorial team, will facilitate their reception among Polish readers.

$$
\star \star \star
$$

The K2 expedition eventually failed and the summit still has not been climbed in winter, but the Polish winter expedition of 2017/2018 will nevertheless become part of the history of Himalayan mountaineering thanks to the magnificent and tragic rescue operation on Nanga Parbat, undertaken by four members of the expedition. Battling extreme conditions, at night, they managed to rescue the French climber Elizabeth Revol. With Tomek Mackiewicz she climbed Nanga Parbat in winter and had serious problems during her descent. The rescuers were not, unfortunately, able to save Mackiewicz, who, after ascending the summit, began to display symptoms of altitude sickness preventing his descent.

Wrockaw, 13 December 2017

Comment - 15 March 2018

Ewa Grzęda 